\title{
Implementasi Kriptografi Kunci Publik dengan Algoritma RSA-CRT pada Aplikasi Instant Messaging
}

\author{
Ashari Arief ${ }^{1}$ dan Ragil Saputra ${ }^{2}$ \\ ${ }^{1,2}$ Jurusan Ilmu Komputer, FSM, Universitas Diponegoro, Semarang \\ ${ }^{1}$ ashariarief@gmail.com, ${ }^{2}$ ragil.saputra@undip.ac.id
}

\begin{abstract}
Abstrak
Instant messaging merupakan salah satu bentuk kemajuan teknologi komunikasi yang mempermudah penyampaian informasi. Saat ini, dengan semakin banyaknya pengguna aplikasi instant messaging berakibat pada dampak negatif berupa penyadapan data khususnya saat terjadi komunikasi yang bersifat rahasia. Algoritma RSA merupakan salah satu satu algoritma dalam kriptografi kunci publik. Pada proses enkripsi dan dekripsi digunakan kunci yang berbeda. Proses dekripsi algoritma RSA sering terjadi kendala karena ukuran kunci dekripsi yang relatif besar dapat memperlambat proses. Untuk mempercepat proses dekripsi, algoritma RSA dapat dimodifikasi dengan algoritma CRT (Chinese Remainder Theorem), sering disebut dengan Algoritma RSA-CRT. Implementasi algoritma kriptografi RSA-CRT pada aplikasi instant messaging pada panjang bit $n$ mulai dari 56 bit sampai 88 bit, proses dekripsi RSA-CRT dua kali lebih cepat dibandingkan proses dekripsi RSA.
\end{abstract}

Kata Kunci: Kriptografi, Kunci publik, RSA-CRT, Instant messaging.

\section{PENDAHULUAN}

Kemajuan teknologi komputer dan telekomunikasi membantu dalam menyelesaikan banyak pekerjaan dengan cepat, akurat, dan efisien. Salah satu kemajuan teknologi komunikasi yaitu menghasilkan aplikasi instant messaging atau pesan instan. Instant messaging merupakan fasilitas komunikasi chatting untuk para pengguna internet sehingga user dapat berkomunikasi dengan cara mengirimkan pesan berupa teks dengan user lain [1]. Namun seiring dengan kemajuan teknologi, dengan semakin banyaknya pengguna yang menggunakan aplikasi instant messaging terdapat dampak negatif berupa penyadapan data khususnya saat terjadi komunikasi yang bersifat rahasia dan penting sehingga aspek keamanan dalam pertukaran informasi dianggap penting.

Kriptografi adalah ilmu yang mempelajari teknik matematika yang berhubungan dengan aspek keamanan informasi seperti kerahasiaan, integritas data, otentikasi entitas, dan otentikasi asal data [2]. Kriptografi bertujuan agar informasi yang bersifat rahasia dan dikirim melalui suatu jaringan, seperti LAN atau internet, tidak dapat diketahui dan dimanfaatkan oleh orang lain atau pihak yang tidak berkepentingan.

RSA merupakan algoritma kriptografi kunci publik atau sering disebut kunci asimetrik (kunci enkripsi dan kunci dekripsi berbeda) sehingga tidak membutuhkan saluran yang aman untuk distribusi kunci. RSA ditemukan oleh tiga peneliti dari MIT (Massachussets Institute of Technology), yaitu Ronald Linn Rivest, Adi Shamir, dan Len Adleman pada tahun 1977 [3]. Keamanan algoritma RSA terletak pada sulitnya memfaktorkan bilangan yang besar menjadi faktor-faktor prima. 
CRT (Chinese Remainder Theorem) merupakan suatu algoritma untuk mengurangi perhitungan aritmatika modular dengan modulus besar untuk perhitungan yang sama untuk masing-masing faktor dari modulus [4]. CRT dapat memperpendek ukuran bit eksponen dekripsi d (merupakan kunci publik RSA atau RSA-CRT) dengan cara menyembunyikan d pada sistem kongruen sehingga mempercepat waktu dekripsi serta dapat digunakan bersama algoritma RSA yang disebut RSA-CRT.

Untuk meningkatkan keamanan dari segi pengiriman pesan yang dibuat dalam saluran yang tidak aman serta modifikasi algoritma RSA dengan menggunakan teorema CRT agar dapat dibandingkan dengan algoritma RSA, perlu dibangun sebuah aplikasi instant messaging dengan mengimplementasikan algoritma kriptografi RSA-CRT.

\section{METODE}

\subsection{Kriptografi Kunci Publik RSA}

Algoritma RSA menggunakan 2 angka (e dan d) sebagai kunci publik dan kunci privat. Pada algoritma RSA e dan $\mathrm{n}$ diumumkan untuk umum sedangkan $\mathrm{d}$ dirahasiakan. Meskipun RSA dapat digunakan untuk mengenkripsi dan mendekripsi pesan, sangat lambat jika pesan tersebut panjang. Oleh karena itu, algoritma RSA berguna untuk pesan singkat. Sejak algoritma menggunakan 2 kunci untuk enkripsi dan dekripsi, algoritma RSA dianggap sebagai contoh kunci asimetrik kriptografi [5]. Desain konseptual dari algoritma RSA dapat disajikan pada Gambar 1.

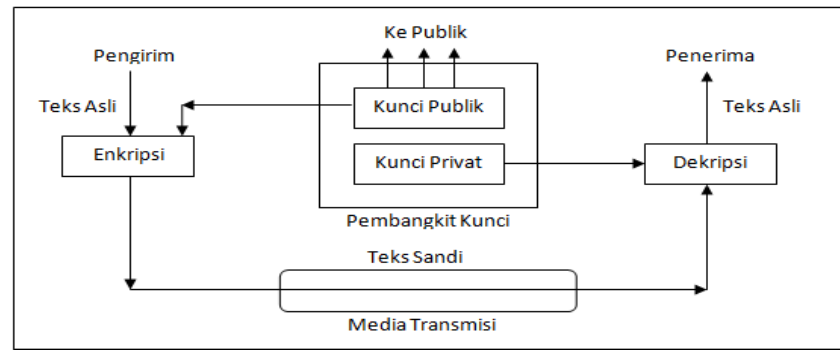

Gambar 1. Konsep kriptografi kunci publik RSA

Algoritma RSA dibagi menjadi 3 langkah [6]:

1. Pembangkit Kunci

a. Pilih 2 bilangan prima besar untuk nilai $p$ dan $q$

b. hitung nilai modulus $n=p \times q$

c. Hitung menggunakan fungsi Euler $\phi(n)=(p-1) x(q-1)$

d. Pilih nilai integer $e$ acak sebagai kunci publik, dengan syarat memenuhi

Greater Common Divisor (GCD) $(e, \phi(n))=1,1<e<\phi(n)$

e. Hitung kunci privat d sehingga $d x e=1(\bmod \phi(n))$

2. Enkripsi

$\mathrm{C}=\mathrm{M}^{e} \bmod n$

3. Dekripsi

$\mathrm{M}=\mathrm{C}^{d} \bmod n$ 


\subsection{CRT (Chinese Remainder Theorem)}

CRT (Chinese Remainder Theorem) merupakan suatu algoritma untuk mengurangi perhitungan aritmatika modular dengan modulus besar untuk perhitungan yang sama untuk masing-masing faktor dari modulus [4].

Terdapat bilangan-bilangan $n_{l}, n_{2}, \ldots, n_{k}$ adalah bilangan bulat positif di mana relatif prima pada pasangan [7]. Contohnya: $\operatorname{FPB}\left(n_{i}, n_{j}\right)=1$ di mana $i \neq j$. Lebih jauh lagi, $n=$ $n_{1}, n_{2}, \ldots, n_{k}$ dan $x_{1}, x_{2}, \ldots, x_{k}$ adalah bilangan bulat. Maka sistem kongruen:

$$
\begin{aligned}
& x \equiv x_{1} \bmod n_{l}, \\
& x \equiv x_{2} \bmod n_{2}, \\
& \cdots \\
& x \equiv x_{k} \bmod n_{k}
\end{aligned}
$$

memiliki solusi yang simultan pada semua kongruen dan dua solusi apapun adalah saling kongruen modulo. Lebih jauh lagi terdapat tepatnya satu solusi antara 0 dan $n$ 1. Solusi unik dari kongruen simultan memenuhi $0 \leq x \leq n$ dapat dihitung dengan rumus (8):

$$
\begin{aligned}
x & =\left(\sum_{i=1}^{k} x_{i} r_{i} s_{i}\right) \bmod n \\
& =\left(x_{1} r_{1} s_{1}+x_{2} r_{2} s_{2}+\ldots+x_{k} r_{k} s_{k}\right) \bmod n
\end{aligned}
$$

Dimana $r_{i}=\frac{n}{n_{i}}$ dan $s_{i}=r_{i}^{-1} \bmod n_{i}$ untuk $i=1,2, \ldots, k$.

Jika bilangan bulat $n_{1}, n_{2}, \ldots, n_{k}$ adalah pasangan relatif prima dan $n=n_{1}, n_{2}, \ldots, n_{k}$, maka untuk semua bilangan bulat a, b pasti akan valid di mana $a \equiv b \bmod n$ jika dan hanya jika $a \equiv b \bmod n_{i}$ untuk setiap $i=1,2, \ldots, k$.

Sebagai konsekuensi dari CRT, setiap bilangan bulat positif $a<n$ dapat direpresentasikan secara unik sebagai sebuah k-tuple $\left[a_{1}, a_{2}, \ldots, a_{k}\right]$ dan sebaliknya. Di mana $a_{i}$ menunjukan sisa / residu $a$ mod $n_{i}$ untuk setiap $i=1,2, \ldots, k$. Konversi $a$ menjadi sistem residu didefinisikan dengan $n_{1}, n_{2}, \ldots, n_{k}$ dilakukan secara sederhana dengan reduksi modular $a$ mod $n^{i}$. Konversi balik dari representasi sisa menjadi "angka-angka standar" adalah lebih sulit seperti yang dibutuhkan dalam kalkulasi pada rumus (7).

Keuntungan dasar dengan menggunakan Chinese Remainder Theorem adalah memungkinkan untuk membagi modulo eksponensial yang besar ke dalam dua eksponensial yang jauh lebih kecil, satu di atas p dan satu di atas q. Dua modulo ini adalah faktor utama dari $n$ yang dikenali.

\subsection{Algoritma RSA dan CRT (RSA-CRT)}

Sistem kriptografi RSA dapat dimodifikasi dengan menggunakan teorema CRT disebut dengan RSA-CRT. Terbukti sistem kriptografi RSA-CRT memiliki waktu komputasi yang lebih singkat daripada sistem kriptografi RSA biasa, yaitu sekitar 4 kali lebih cepat [8]. 
Algoritma RSA-CRT dibagi menjadi 3 langkah:

\section{Pembangkit Kunci RSA-CRT}

Pada dasarnya RSA-CRT sama dengan RSA biasa tetapi memanfaatkan teorema CRT untuk memperpendek ukuran bit eksponen deksipsi $d$ dengan cara menyembunyikan $d$ pada sistem kongruen sehingga mempercepat waktu dekripsi. Berikut algoritma pembangkit kunci RSA-CRT:

a. Bangkitkan bilangan prima besar $p$ dan $q$

b. Lihat rumus (1).

c. Lihat rumus (2).

d. Lihat rumus (3).

e. Lihat rumus (4).

f. $\mathrm{dP}=d \bmod (p-1)$

g. $\mathrm{dQ}=d \bmod (q-1)$

h. $\mathrm{qInv}=q^{-1}$ pada $\mathrm{Z}_{p}$

i. $K_{\text {publik }}=(e, n), K_{\text {privat }}=(\mathrm{dP}, \mathrm{dQ}, \mathrm{qInv}, p, q)$

\section{Enkripsi RSA-CRT}

Kunci publik RSA-CRT sama dengan sistem RSA yaitu $(e, n)$ sehingga algoritma enkripsi tidak mengalami perubahan yaitu dengan menggunakan fungsi eksponensial modular yaitu lihat pada rumus (5).

\section{Dekripsi RSA-CRT}

Diberikan teks sandi seperti rumus (5) dan kunci privat (dP, dQ, qInv, $p, q$ )

dekripsi RSA-CRT seperti berikut:

$$
\begin{aligned}
& \text { a. } m_{1}=C^{\mathrm{dP}} \bmod p \\
& \text { b. } m_{2}=C^{\mathrm{dQ}} \bmod q \\
& \text { c. } h=\mathrm{qInv} \cdot\left(m_{1}-m_{2}\right) \bmod p \\
& \text { d. } \mathrm{M}=m_{2}+h \cdot q
\end{aligned}
$$

\subsection{Algoritma Fast Modular Exponentiation}

Algoritma fast modular exponentiation merupakan algoritma untuk menghitung suatu modular exponentiation dengan cepat. Rumus modular exponentiation dapat dilihat pada rumus (17).

$\mathrm{a}^{\mathrm{b}} \bmod \mathrm{c}$

Algoritma fast modular exponentiation dibagi menjadi 3 langkah [9]:

1. Ubah b pada rumus (17) menjadi binary dengan ketentuan pada Tabel 1.

Tabel 1. Ketentuan Binary

Mulai dari digit paling kanan, dengan nilai awal $\mathrm{k}=0$ dan untuk setiap digit:

a. Jika digit bernilai 1 , maka ubah 1 menjadi $2^{\wedge} \mathrm{k}$, jika tidak berinilai 1 maka abaikan.

b. Tambah 1 pada nilai $k$, kemudian lakukan tahapan yang sama untuk digit sebelah kirinya.

2. Pada rumus 2.5 hitung mod $\mathrm{c}$ dari 2 perpangkatan yang $\leq \mathrm{b}$.

3. Pada rumus 2.5 gunakan sifat perkalian modular untuk digabungkan dengan perhitungan nilai mod c. 


\subsection{Pemrograman Soket dengan TCP (Transmission Control Protocol)}

Sebagian besar aplikasi terdiri dari sepasang proses komunikasi, dengan dua proses dalam setiap pasangan mengirim pesan satu sama lain. Setiap pesan yang dikirim dari satu proses yang lain harus melalui jaringan yang mendasarinya. Sebuah proses mengirimkan pesan ke dalam, dan menerima pesan dari jaringan melalui antarmuka perangkat lunak disebut soket [10].

Aplikasi jaringan banyak terdiri dari sepasang program-program klien dan server program yang berada di dua sistem akhir yang berbeda. Ketika kedua program dijalankan, klien dan proses server dibuat, dan proses ini berkomunikasi satu sama lain dengan membaca dari dan menulis ke soket. Karena soket memainkan peran sentral dalam klien/server mengembangkan aplikasi klien/server juga disebut sebagai pemrograman soket, dapat dilihat pada Gambar 2.

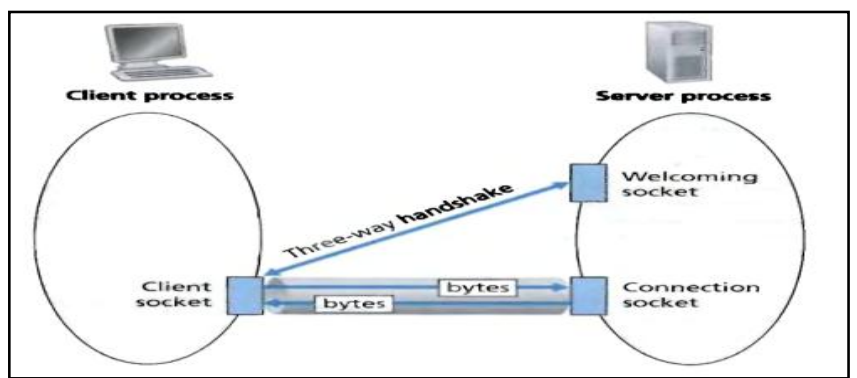

Gambar 2. Client-Socket, Welcoming Socket, dan Connection Socket

Pemrograman soket dengan TCP adalah pemrograman soket yang berorientasi koneksi dan menyediakan reliable (handal) byte-stream yang menjamin bahwa proses server akan menerima (melalui koneksi soket) setiap byte dalam urutan yang dikirim. Selain itu proses klien tidak hanya mengirimkan byte tetapi juga menerima byte dari koneksi soket. Untuk proses komunikasi melalui soket TCP dapat dilihat pada Gambar 3.

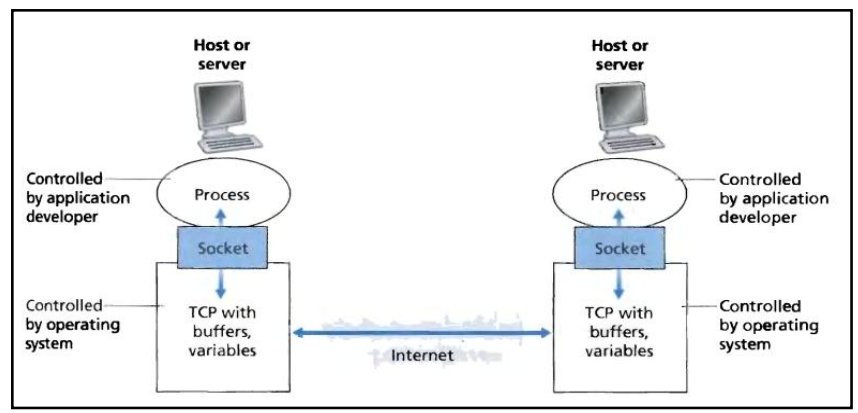

Gambar 3. Proses komunikasi melalui soket TCP

\section{HASIL DAN PEMBAHASAN}

\subsection{Mengolah Server dan Client}

Aplikasi instant messaging menggunakan algoritma kriptografi RSA-CRT dengan pemrograman soket berbasis TCP, sehingga dibuatnya class TcpListener dengan port 8888 dan class TcpClient (untuk server) seperti kode berikut: 
Dim serverSocket As New Tcplistener(8888)

'mendeklarasikan variabel serverSocket sebagai Tcplistener (kelas yg berfungsi 'mendengarkan koneksi dari tcp klien) dengan port 8888

Dim clientSocket As Tcpclient

"mendeklarasikan variabel clientsocket sebagai Tcpclient (kelas yg menyediakan "koneksi client untuk layanan jaringan TCP)

class TcpClient (untuk client) seperti kode berikut:

Dim clientSocket As New System.Net.Sockets.TcpClient

serta dibuatnya inisialisasi port 8888 untuk melakukan hubungan (pada sisi client) seperti kode berikut:

clientSocket.Connect (ip.Text, 8888)

Pada sisi client terdapat masukan IP (localhost) dan nama (Andi) untuk pengguna pertama, pengguna kedua dengan masukan IP (localhost) dan nama (Budi), seperti pada Gambar 4 untuk sisi client dan Gambar 5 untuk sisi server.

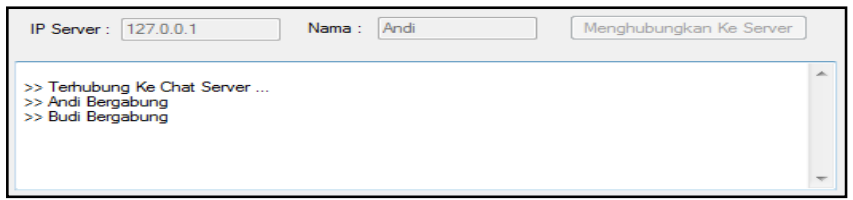

Gambar 4. Tampilan sisi client

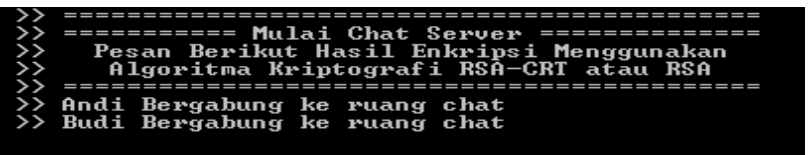

Gambar 5. Tampilan sisi server

\subsection{Mengolah Kunci}

Pada alur proses mengolah kunci, Andi membangkitkan kunci dengan nilai $\mathrm{P}=41$ dan nilai $\mathrm{Q}=43$, seperti pada gambar 6 sedangkan Budi menggunakan kunci acak seperti pada gambar 7. Gambar 8 merupakan tampilan server setelah menerima dua kunci publik dari 2 pengguna.

Pada Gambar 6, Andi memiliki kunci publik e = 341 dan $\mathrm{n}=1763$ dengan waktu pengolahan kunci selama 0 milidetik. Pada Gambar 7, Budi membangkitkan kunci secara acak, dengan kunci publik e $=6252963$ dan $\mathrm{n}=6820243$ dengan waktu pengolahan kunci selama 1088 milidetik, serta memiliki maksimum karakter yang digunakan untuk mengirimkan pesan yaitu 1.350 karakter dikarenakan nilai $\mathrm{n}$ milik Andi kurang dari 1.000.000.

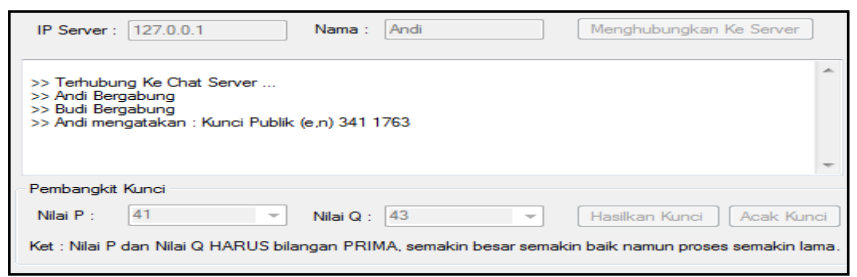

Gambar 6. Andi membangkitkan kunci dengan nilai $\mathrm{p}=41, \mathrm{q}=43$ (client) 


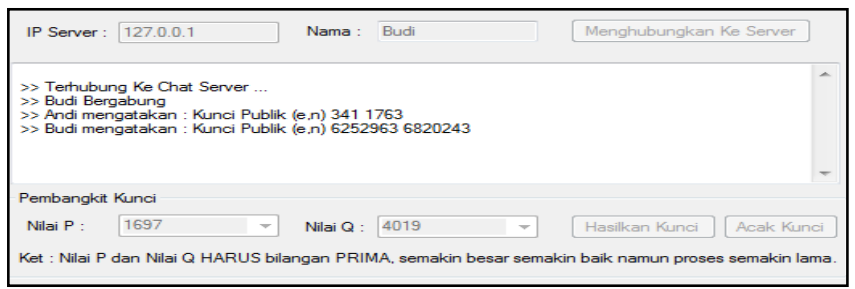

Gambar 7. Budi membangkitkan kunci acak (client)

Kunci publik Andi digunakan untuk proses enkripsi ketika Budi mengirimkan pesan, begitu juga sebaliknya kunci publik Budi digunakan untuk proses enkripsi ketika Andi mengirimkan pesan. Proses ini dapat dilihat pada Gambar 8.

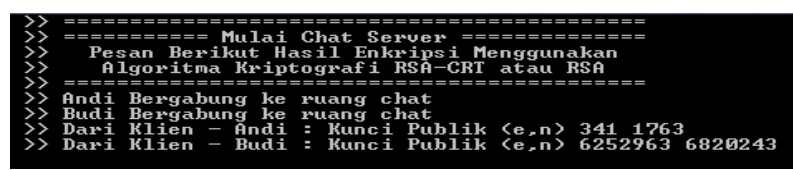

Gambar 8. Server menerima kunci publik (server)

\subsection{Mengolah Pesan}

Pada alur proses mengolah pesan, Budi mengirimkan pesan "password brankas A7\%*g(8L\#/C+!" seperti pada Gambar 9 dengan menggunakan kunci publik Andi (e $=341, \mathrm{n}=1763)$ serta waktu proses enkripsi 0 milidetik. Pada Gambar 10, server menerima pesan Budi yang kemudian akan disebarkan server ke Andi. Andi menerima pesan Budi dengan menggunakan metode dekripsi RSA-CRT. Aplikasi mendekripsikan pesan Budi menggunakan kunci privat Andi $(\mathrm{dP}=21, \mathrm{dQ}=17$, qInv $=21, \mathrm{p}=41, \mathrm{q}=43$ ) dengan waktu proses dekripsi 0 milidetik seperti pada gambar 14. Andi membalas pesan budi dengan pesan "terima kasih" seperti pada Gambar 11 dengan menggunakan kunci publik Budi $(e=6252963, \mathrm{n}=6820243)$ serta waktu proses enkripsi 0 milidetik.

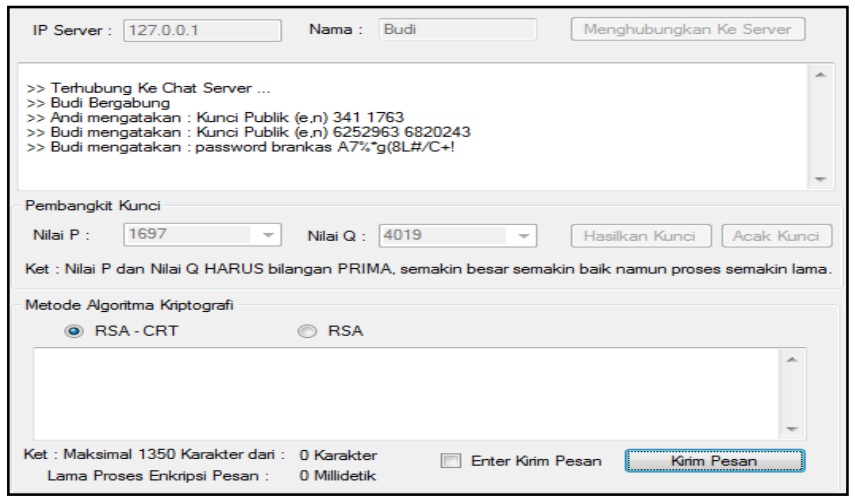

Gambar 9. Budi mengirim pesan (client)

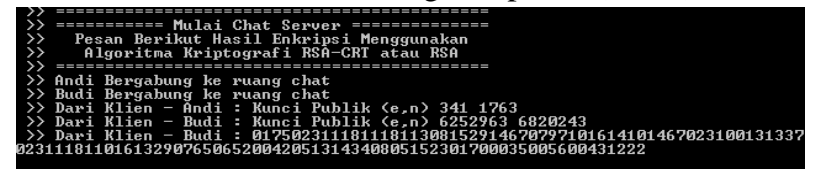

Gambar 10. Server menerima pesan Budi (server) 


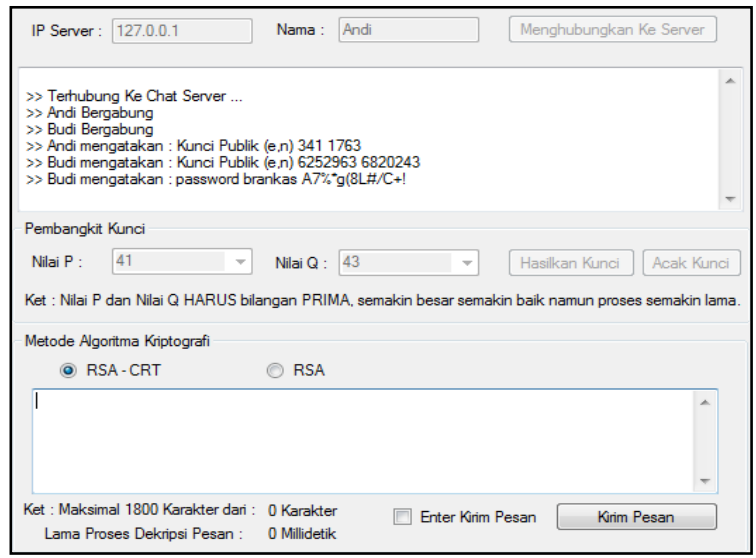

Gambar 11. Andi menerima pesan (client)

\section{Pengujian}

Pengujian algoritma kriptografi RSA-CRT pada aplikasi instant messaging yang utama adalah membandingkan kecepatan dekripsi antara algoritma kriptografi RSA dengan algoritma kriptografi RSA-CRT. Waktu yang digunakan untuk melakukan proses dekripsi sebagai perbandingan antar kedua algoritma kriptografi.

Pengujian dilakukan dengan menggunakan 1800 karakter dummy, jumlah bit $\mathrm{n}$ yang digunakan mulai dari 56 bit sampai 88 bit, dikarenakan pesan yang digunakan untuk melakukan pengujian yaitu 1.800 karakter sehingga mempunyai syarat nilai $n$ harus lebih besar atau sama dengan 1.000.000. Hasil pengujian dapat dilihat pada Tabel 2.

Tabel 2. Pengujian algoritma kriptografi RSA-CRT

\begin{tabular}{clllllcc}
\hline $\begin{array}{c}\text { Bit } \\
\mathbf{N}\end{array}$ & Nilai P & Nilai Q & \multicolumn{1}{c}{ Nilai N } & Nilai E & $\begin{array}{c}\text { Olah } \\
\text { Kunci } \\
(\mathbf{m s})\end{array}$ & $\begin{array}{c}\text { Dekripsi } \\
\text { RSA-CRT } \\
(\mathbf{m s})\end{array}$ & $\begin{array}{c}\text { Dekrip } \\
\text { si RSA } \\
(\mathbf{m s})\end{array}$ \\
\hline $\mathbf{5 6}$ & 8.669 & 541 & 4.689 .929 & 2.804 .371 & 1.248 & 32 & 50 \\
$\mathbf{6 4}$ & 8.311 & 5.861 & 48.710 .771 & 24.330 .337 & 8.670 & 30 & 38 \\
$\mathbf{7 2}$ & 31.511 & 14.489 & 456.562 .879 & 360.447 .427 & 70.611 & 47 & 70 \\
$\mathbf{8 0}$ & 80.803 & 59.747 & 4.827 .736 .841 & 1.703 .007 .661 & 146.809 & 37 & 84 \\
$\mathbf{8 8}$ & 333.997 & 149.099 & 49.798 .618 .703 & 36.157 .708 .349 & 15.493 .691 & 30 & 100 \\
\hline
\end{tabular}

Berdasarkan hasil pengujian algoritma kriptografi RSA-CRT yang dapat dilihat pada Tabel 2 dapat diberi kesimpulan dengan rata-rata kecepatan yang dapat dilihat pada Tabel 3.

Tabel 3. Pengujian kecepatan algoritma kriptografi RSA-CRT

\begin{tabular}{ccccc}
\hline No. & \multirow{2}{*}{ Bit N } & $\begin{array}{c}\text { Waktu Dekripsi } \\
\text { RSA-CRT }(\mathbf{m s})\end{array}$ & $\begin{array}{c}\text { Waktu Dekripsi RSA } \\
(\mathbf{m s})\end{array}$ & $\begin{array}{c}\text { Kecepatan (RSA / RSA- } \\
\text { CRT) }\end{array}$ \\
\hline 1 & 56 & 32 & 50 & 1,6 kali lebih cepat \\
2 & 64 & 30 & 38 & 1,3 kali lebih cepat \\
3 & 72 & 47 & 70 & 1,5 kali lebih cepat \\
4 & 80 & 37 & 84 & 2,3 kali lebih cepat \\
5 & 88 & 30 & 100 & 3,3 kali lebih cepat \\
& & & Rata - rata & 2 kali lebih cepat \\
\hline
\end{tabular}


Dari pengujian kecepatan algoritma kriptografi RSA-CRT yang dapat dilihat pada Tabel 3, dapat diberi kesimpulan semakin besar jumlah bit $\mathrm{n}$ maka kemungkinan besar kecepatan waktu dekripsi RSA-CRT lebih cepat dan dari 5 pengujian yang dilakukan mulai bit $\mathrm{n}=56$ bit sampai bit $\mathrm{n}=88$ bit dapat disimpulkan kecepatan yang diperolah rata-rata yaitu dua kali lebih cepat ketika menggunakan dekripsi RSA-CRT dibandingkan menggunakan dekripsi RSA.

\section{SIMPULAN}

Implementasi algoritma kriptografi kunci publik dengan algoritma RSA-CRT pada aplikasi instant messaging, proses dekripsi menggunakan algoritma RSA-CRT untuk 1.800 karakter dengan bit $\mathrm{n}$ dari 56 bit sampai 88 bit memiliki kecapatan rata-rata dua kali lebih cepat dibandingkan menggunakan algoritma RSA. Semakin besar panjang string, nilai n kemungkinan besar semakin cepat waktu dekripsi menggunakan RSACRT.

\section{REFERENSI}

[1] Zuliarso, E. \& Februariyanti, H., 2013. Pemanfaatan Instant Messaging untuk Aplikasi Layanan Akademik. Jurnal Teknologi Informasi DINAMIK. Vol. 18(2): 112-121.

[2] Menezes, A. J., Oorschot, P. C. v. \& Vanstone, S. A., 1996. Handbook of Applied Cryptography. 1st penyunt. Boca Raton: CRC Press.

[3] Rivest, R. L., Shamir, A. \& Adleman, L., 1978. A Method for Obtaining Digital Signatures and Public-Key Cryptosystems. Communications of the ACM. Vol. 21(2): 120-126.

[4] Tilborg, H. C. A. v., 2005. Ecnyclopedia of Cryptography and Security. New York: SpringerScience+Business Media.

[5] Ashioba, N. C. \& Yoro, R. E., 2014. RSA Cryptosystem using Object-Oriented Modeling Technique. International Journal of Information and Communication Technology Research. Vol. 4(2): 57-61.

[6] Garg, V. \& Arunachalam, V., 2011. Architectural Analysis of RSA Cryptosystem on FPGA. International Journal of Computer Applications. Vol. 26(8): 30-34.

[7] Pohan, R. Y., 2007. Algoritma RSA dengan Chinese Remainder Theorem dan Hensel Lifting. Bandung, Jurusan Teknik Informatika ITB.

[8] Sadikin, R., 2012. Kriptografi untuk Keamanan Jaringan dan Implementasinya dalam Bahasa Java. Yogyakarta: Penerbit ANDI.

[9] Academy, K., 2015. Fast Modular Exponentiation. (Online), (https://www.khanacademy.org/computing/computer-science/cryptography/ modarithmetic/a/fast-modular-exponentiation, diakses 01 November 2015)

[10] Kurose, J. F. \& Ross, K. W., 2010. Computer Networking: A Top-Down Approach. 5th penyunt. Boston: Pearson Education. 